\title{
Representações sociais de acadêmicos de enfermagem sobre a empatia no cuidado:
}

\section{Abordagem ao paciente queimado}

\author{
Social representations of nursing academics about empathy in care: Approach to burned patients \\ Representaciones sociales de los académicos de enfermería sobre la empatía en la atención:
}

Enfoque al paciente quemado

Recebido: 21/04/2021 | Revisado: 28/04/2021 | Aceito: 01/05/2021 | Publicado: 15/05/2021

\author{
Carolina Rodrigues Milhorini \\ ORCID: https://orcid.org/0000-0001-8228-9327 \\ Universidade Estadual de Londrina, Brasil \\ E-mail: crmilhorini@gmail.com \\ Juliana Helena Montezeli \\ ORCID: https://orcid.org/0000-0003-4522-9426 \\ Universidade Estadual de Londrina, Brasil \\ E-mail: jhmontezeli@hotmail.com \\ Andréia Bendine Gastaldi \\ ORCID: https://orcid.org/0000-0002-4081-993X \\ Universidade Estadual de Londrina, Brasil \\ E-mail: abgastaldi@gmail.com \\ Regina Célia Bueno Rezende Machado \\ ORCID: https://orcid.org/0000-0001-5531-7345 \\ Universidade Estadual de Londrina, Brasil \\ E-mail: reginam_rezende@yahoo.com.br \\ Susany Franciely Pimenta \\ ORCID: https://orcid.org/0000-0002-1170-1836 \\ Universidade Estadual de Londrina, Brasil \\ E-mail: susanypimenta@ hotmail.com \\ Aline Franco da Rocha \\ ORCID: https://orcid.org/0000-0002-1187-0672 \\ Universidade Estadual de Londrina, Brasi \\ E-mail: liny.afr@hotmail.com \\ Flávia Gagliano Guergoleti \\ ORCID: https://orcid.org/0000-0002-8474-2807 \\ Universidade Estadual de Londrina, Brasil \\ E-mail: flaviagagliano@ hotmail.com
}

\begin{abstract}
Resumo
Objetivo: apreender as representações sociais de acadêmicos de enfermagem acerca da empatia no cuidado ao paciente queimado. Método: pesquisa qualitativa realizada por meio de entrevista semiestruturada com 12 graduandos do último ano de enfermagem de uma universidade estadual pública paranaense, que passaram por práticas acadêmicas obrigatórias em um Centro de Tratamento de Queimados. Os dados foram tratados pela análise de conteúdo e discutidos à luz da Teoria das Representações Sociais. Resultados: emergiram quatro categorias empíricas: 1) Representações conceituais da empatia; 2) Representações da empatia como pilar da subjetividade do cuidado; 3) Representações da empatia como apoio à prática profissional do enfermeiro e; 4) Representações pessoais sobre a empatia vivenciada pelos acadêmicos. A empatia foi configurada como ferramenta auxiliadora na consolidação de um cuidado integral e despertou outras habilidades sociais nos participantes, garantindo cuidado humanizado. Conclusão: A empatia repercute positivamente no cuidado ao paciente queimado, sendo necessário incentivá-la desde a formação acadêmica para que os profissionais adquiram um olhar voltado à perspectiva de sua clientela, permitindo o fortalecimento do cuidado, vínculo, comunicação e ética.
\end{abstract}

Palavras-chave: Assistência integral à saúde; Queimaduras; Empatia; Enfermagem.

\section{Abstract}

Objective: to apprehend the social representations of nursing students about empathy in the care of burned patients. Method: qualitative research carried out through a semi-structured interview with 12 undergraduate nursing students from a public state university in Paraná, who underwent mandatory academic practices at a Burns Treatment Center. The data were treated by content analysis and discussed in the light of the Theory of Social Representations. Results: four empirical categories emerged: 1) Conceptual representations of empathy; 2) Representations of empathy as a pillar of the subjectivity of care; 3) Representations of empathy as support for the nurse's professional practice and; 4) 
Personal representations about the empathy experienced by academics. Empathy was configured as an auxiliary tool in the consolidation of comprehensive care and aroused other social skills in the participants, ensuring humanized care. Conclusion: Empathy has a positive impact on the care of burned patients, and it is necessary to encourage it since the academic training so that professionals acquire a look focused on the perspective of their clientele, allowing the strengthening of care, bonding, communication and ethics.

Keywords: Comprehensive health care; Burns; Empathy; Nursing.

\section{Resumen}

Objetivo: aprehender las representaciones sociales de estudiantes de enfermería sobre la empatía en el cuidado del paciente quemado. Método: investigación cualitativa realizada mediante entrevista semiestructurada a 12 estudiantes de pregrado en enfermería de una universidad pública estatal de Paraná, quienes realizaron prácticas académicas obligatorias en un Centro de Tratamiento de Quemaduras. Los datos fueron tratados mediante análisis de contenido y discutidos a la luz de la Teoría de las Representaciones Sociales. Resultados: surgieron cuatro categorías empíricas: 1) Representaciones conceptuales de la empatía; 2) Representaciones de la empatía como pilar de la subjetividad del cuidado; 3) Representaciones de empatía como apoyo a la práctica profesional de la enfermera y; 4) Representaciones personales sobre la empatía vivida por los académicos. La empatía se configuró como herramienta auxiliar en la consolidación de la atención integral y despertó otras habilidades sociales en los participantes, garantizando un cuidado humanizado. Conclusión: La empatía tiene un impacto positivo en el cuidado de los pacientes quemados, y es necesario incentivarla desde la formación académica para que los profesionales adquieran una mirada enfocada en la perspectiva de su clientela, permitiendo el fortalecimiento del cuidado, la vinculación, la comunicación y la ética.

Palabras clave: Atención integral de salud; Quemaduras; Empatía; Enfermería.

\section{Introdução}

Habilidades Sociais (HS) são um conjunto de comportamentos apresentados por um indivíduo que o ajudam a lidar com situações interpessoais cotidianas, levando a um resultado positivo e que preserve a cultura, a autoestima e o bem-estar de todos os envolvidos (Del Prette \& Del Prette, 2017). Como a enfermagem se caracteriza como prática social, é imprescindível que as habilidades relacionais sejam efetivas, tornando o processo de trabalho humanizado e com qualidade técnica (Del Prette \& Del Prette, 2017).

A empatia está entre as Habilidades Sociais e corresponde à capacidade de identificar, compreender e experimentar o pensamento e sentimento do outro, de forma a validá-lo (Del Prette \& Del Prette, 2017). Ela, unida ao processo de comunicação, corresponde a uma ferramenta que transforma as relações interpessoais de serviços assistenciais, trazendo benefícios para todos os atores envolvidos no processo de cuidar (Savieto \& Leão, 2016), sobretudo no concernente ao paciente queimado.

Ao considerar grandes queimaduras, trauma em que o indivíduo experimenta dor intensa, ansiedade e insegurança, bem como distorção da autoimagem em casos de amputações ou desfiguração, a empatia repercute nas relações entre paciente, equipe e família, favorecendo a comunicação efetiva que estimule a expressão dos seus sentimentos e necessidades, assim como preparar o paciente e família para o que poderá ocorrer nos tempos seguintes (Antoniolli et al., 2018; Júnior, Azevêdo \& Crepaldi, 2017).

Considerando que a empatia deve ser desenvolvida no enfermeiro desde a sua formação, que as queimaduras são uma especialidade que diferem das demais experiências ao longo da graduação, principalmente no tocante aos aspectos subjetivos envolvidos no cuidado às vítimas e o papel primordial da empatia na assistência de enfermagem de qualidade a esta clientela, objetivou-se nesta investigação apreender as representações sociais de acadêmicos de enfermagem acerca da empatia no cuidado ao paciente queimado.

\section{Metodologia}

Trata-se de uma pesquisa qualitativa, desenvolvida de junho a agosto de 2019, em uma instituição de ensino superior pública do Norte do Paraná, Brasil, cujo hospital universitário contava com Centro de Tratamento de Queimados (CTQ). 
No curso de graduação em enfermagem desta instituição, utiliza-se o currículo integrado e as etapas de aprendizado são divididas em módulos específicos. Esta experiência favorece a análise crítica e reflexiva das mais diversas situações, culminando em autoconhecimento e elaboração de HS ao longo da trajetória acadêmica, como a empatia, que qualifica as relações interpessoais tanto no âmbito acadêmico, quanto profissional (Savieto \& Leão, 2016; Alves, Alves, Menezes \& Moraes, 2017).

Foi realizada uma entrevista semiestruturada individual audiogravada com 12 graduandos de enfermagem do último ano, de um total de 53, escolhidos intencionalmente, considerando os seguintes critérios de inclusão: ser graduando do último ano de enfermagem; ter participado das práticas curriculares no CTQ da instituição durante o módulo de Assistência ao Paciente Crítico e ter demonstrado assiduidade e proatividade para realizar procedimentos no setor. Excluíram-se aqueles que não alcançaram os desempenhos necessários para aprovação no módulo de Assistência ao Paciente Crítico.

O número de participantes foi determinado pela amostragem por saturação, sendo que a partir da décima entrevista não emergiram novas alocuções. É utilizada para determinar o tamanho de uma amostra em estudo qualitativo, interrompendose a captação de novos dados. Ocorre quando as informações não são mais novidade, passando a ser redundantes, diante daquelas já obtidos. Assim, deixa de ser relevante prosseguir com a coleta, visto que as informações fornecidas pelos novos participantes não mais contribuem para o aperfeiçoamento da reflexão teórica (Fontanella, Ricas \& Turato, 2008).

Utilizou-se um instrumento norteador composto por uma parte inicial de caracterização do estudante seguida por sete questões abertas: o que você entende por empatia?; Qual a importância da empatia na prática profissional do enfermeiro?; O que representa, para você, prestar assistência de enfermagem de modo empático?; Qual a representação da empatia, para você, no processo de cuidar realizado pela enfermagem?; Há especificidades empáticas a serem praticadas pelo enfermeiro no cuidado ao paciente queimado? Explique; Descreva um episódio que você vivenciou em que a empatia esteve presente no cuidado ao paciente queimado durante o estágio no CTQ e; Descreva um episódio que você vivenciou em que faltou empatia no cuidado ao paciente queimado durante o estágio no CTQ.

As falas foram transcritas em versão literal dos depoimentos, mantendo a linguagem própria dos indivíduos, sem considerar os aspectos comportamentais ou corporais demonstrados pelos estudantes. Os dados foram tratados pela Análise de Conteúdo, compreendendo as etapas de pré-análise, exploração do material e o tratamento dos resultados com as inferências e as interpretações (Bardin, 2011). Neste estudo, os trechos dos diálogos que ilustram as categorias foram codificados entre P1 e P12 (participante número um a participante número 12), a fim de manter o anonimato dos inquiridos.

As interpretações, inferências e discussões foram ancoradas na Teoria das Representações Sociais de Serge Moscovici, o qual compreende que as relações sociais existentes no cotidiano são frutos de representações sociais, que são facilmente apreendidas (Moscovici, 2013).

Para ser viabilizado, este estudo recebeu aprovação no comitê de ética em pesquisas da instituição, sob o número 3.270.209, CAAE 08627619.5.0000.5231 e foi fornecido o Termo de Consentimento Livre e Esclarecido (TCLE) em duas vias para os estudantes assinarem.

\section{Resultados}

Dos entrevistados, nove eram do sexo feminino e três do sexo masculino, com idades entre 20 e 29 anos. $80 \%$ dos participantes verbalizaram interesse pela clientela, sendo que 50\% pretendiam seguir carreira na área de atendimento ao paciente crítico, incluindo o grande queimado.

A análise de conteúdo permitiu a emersão das seguintes categorias empíricas: 1) Representações conceituais da empatia; 2) Representações da empatia como pilar da subjetividade do cuidado; 3) Representações da empatia como apoio à prática profissional do enfermeiro e 4) Representações pessoais sobre a empatia vivenciada pelos acadêmicos no CTQ. 


\section{Categoria 1: representações conceituais da empatia}

Nesta primeira categoria, os estudantes demonstraram possuir entendimento adequado sobre o termo "empatia":

Empatia é você se colocar no lugar do outro, considerar o que ele está passando - P1

É você compreender a situação do outro e se colocar no lugar do outro. - $\mathrm{P} 4$

Entretanto, ainda que de maneira idiossincrática, houve um participante que precisou ser elucidado sobre tal significado antes do prosseguimento da entrevista, por confundir empatia com piedade, como mostrado a seguir:

(...) é um sentimento de pena, porque a gente tem dó do paciente queimado que está ali, naquela situação. - P2

Categoria 2: representações da empatia como pilar da subjetividade do cuidado

O Quadro 1 clarifica as principais representações dialogadas pelos participantes durante as entrevistas no tocante aos aspectos subjetivos do cuidado e que são favorecidos por uma prática empática.

Quadro 1: Representações subjetivas do cuidado favorecidas pela empatia na ótica de acadêmicos de enfermagem, Londrina, 2019.

\begin{tabular}{|c|c|}
\hline esentação & Exemplos de falas \\
\hline $\begin{array}{l}\text { Valorização de } \\
\text { aspectos além do } \\
\text { biológico durante o } \\
\text { cuidado }\end{array}$ & $\begin{array}{l}\text { A empatia no processo de cuidar do queimado significa que você tem que olhar todas as } \\
\text { necessidades, globalmente, não só o que ele está apresentando naquele momento (DOENÇA); é } \\
\text { cuidar do paciente de forma física, psicológica e social. - P3 } \\
\text { Representa um cuidado integral, biopsicossocial às vítimas de queimadura. - P6 }\end{array}$ \\
\hline $\begin{array}{l}\text { Promoção de um } \\
\text { cuidado ético }\end{array}$ & $\begin{array}{l}\text { É não julgar o paciente, o próximo, ou o problema dele; é uma questão de ética, pra manter esse } \\
\text { problema em sigilo. - } \mathrm{P} 2\end{array}$ \\
\hline $\begin{array}{l}\text { Humanização da } \\
\text { assistência }\end{array}$ & $\begin{array}{l}\text { Juntar a empatia ao trabalho do enfermeiro é muito importante, pois humaniza o cuidado prestado } \\
\text { ao paciente. - } \mathrm{P} 7 \\
\text { Se a gente tem empatia, se colocando no lugar do outro, nossas açôes serão melhores e mais } \\
\text { humanizadas. - P9 }\end{array}$ \\
\hline $\begin{array}{l}\text { Proporciona criação } \\
\text { de vínculo }\end{array}$ & $\begin{array}{l}\text { Em um processo empático, é como se você criasse um vínculo com o paciente e isso garante a melhor } \\
\text { assistência prestada possível. - P11 }\end{array}$ \\
\hline $\begin{array}{l}\text { Contribuição para } \\
\text { enfrentamento do }\end{array}$ & $\begin{array}{l}\text { (...) algumas queimaduras podem atingir áreas essenciais, por exemplo a mão, que é um lugar que } \\
\text { ele expõe, a face também (...) ele não vai mais ser do jeito que era antes e precisa aprender a lidar } \\
\text { com essa mudança. Trabalhando nisso empaticamente, desde que o paciente sofreu a queimadura até } \\
\text { a alta, vai ser mais fácil dele lidar quando sair do hospital. - } \mathrm{P} 7 \\
\text { A gente tem que ter empatia para ajudar a pessoa a se compreender e entender que agora ela vai ter } \\
\text { uma aparência diferente, aceitar, e vai ter toda aquela questão do psicológico, para que ela não tente } \\
\text { nada que a auto prejudique. - P8 } \\
\text { Eu acho que o que se destaca é a aparência depois do acidente (...) que é um dos pontos que o } \\
\text { enfermeiro tem que ter empatia ao realizar o cuidado e abordar de forma integral. - P12 }\end{array}$ \\
\hline
\end{tabular}


Fonte: Autores.

Categoria 3: representações da empatia como apoio à prática profissional do enfermeiro

Os participantes mencionaram que uma prática empática contribui para a Sistematização da Assistência de Enfermagem (SAE), como mostram estes excertos:

A empatia ajuda a formular um plano de cuidados adequado, individualizado e que atenda realmente às necessidades do queimado. - $\mathrm{P} 3$

Se a gente não conseguir entender o que uma situação de queimadura representa para a pessoa, a gente vai oferecer um cuidado, muitas vezes, inadequado às suas necessidades. Então, se forem consideradas as situações individuais, é possível fazer um plano de cuidados pra aquela pessoa, específico pra ela. - P8

Outro ponto salientado pelos acadêmicos nesta categoria foi que a empatia é importante para fortalecer a qualidade do cuidado, como ilustra este trecho:

A empatia é um instrumento pra você trazer qualidade ao atendimento do paciente, na assistência que você vai prestar nos casos de queimaduras. - $\mathrm{P} 4$

Uma terceira questão enfatizada pelos entrevistados foi que a empatia é aliada de uma adequada prática comunicacional no cotidiano do CTQ, como pode ser conferido nos seguintes exemplos:

Para você ser um bom enfermeiro, você tem que ter uma boa comunicação e, então, você consegue atingir a empatia. $-\mathrm{P} 3$

A empatia é fundamental (...) porque se nós não tratarmos os outros com empatia, o paciente ou até mesmo os acompanhantes, como vamos conseguir falar com o paciente ou acompanhante sobre o que está acontecendo? - P8

Os profissionais que trabalham com os queimados são bem empáticos, porque eles têm uma boa comunicação com os pacientes, inclusive, perguntando como eles estavam em relação à família. - P9

Categoria 4: representações pessoais sobre a empatia vivenciada pelos acadêmicos no CTQ

As vivências proporcionadas pelas atividades práticas desenvolvidas no CTQ aos acadêmicos de enfermagem despertaram representações pessoais no concernente à empatia. A primeira delas foi a contribuição para lidar com os próprios sentimentos, evidenciada nesta fala:

A empatia no cuidado ao queimado trouxe, principalmente, crescimento profissional, mas também, de certa forma, fez com que eu aprendesse a lidar com as minhas próprias emoções. - P11

Contudo, ainda que a grande maioria dos discursos tenha destacado aspectos positivos do cotidiano no CTQ quanto à empatia praticada durante o atendimento aos pacientes, é relevante discorrer que, em alguns episódios, imperou a falta de empatia por parte de alguns profissionais, gerando sentimento de raiva nos estudantes: 
O médico falou ao familiar que a paciente ia morrer, que ela não ia melhorar (...) sem nenhuma preparação antes. Gerou-me um pouco de raiva (...) eles não veem muito a humanização, tratam a doença e acabou. Não ficam se preocupando com os sentimentos dos outros. - P1

A gente vê na prática que os profissionais do CTQ, muitas vezes, não são empáticos e isso me gerou um sentimento de revolta. $-\mathrm{P} 2$

Um paciente que foi fazer desbridamento, ainda não estava totalmente sedado e o pessoal começou a tocar na lesão dele, ele ainda não estava totalmente anestesiado, estava sentindo e começou a gritar. Isso foi muita falta de empatia porque não esperaram nem o paciente ser totalmente sedado, foi bem marcante pra mim. - $\mathrm{P9}$

\section{Discussão}

Na categoria 1, os estudantes alcançavam a compreensão sobre empatia e buscavam aplicá-la no seu cotidiano, porém, em alguns momentos demonstraram confusões entre o conceito e os sentimentos despertados.

Para que uma relação empática resulte em benefícios, é necessário que haja envolvimento emocional de um indivíduo com o outro. Isso desperta sentimentos confortantes e consoladores, uma vez que a empatia tem como principal objetivo validar o sentimento do outro e dar significado social a ele. As repercussões vão desde aumentar a autoestima até promover o vínculo (Del Prette \& Del Prette, 2017).

Entretanto, a empatia exige um grande desprendimento dos valores morais, desenvolvimento da responsabilidade emocional e automonitoramento. Na ausência disso, as relações são desviadas para a pró-empatia ou simpatia (Del Prette \& Del Prette, 2017).

As reações pró-empáticas ocorrem quando se compreende o problema do outro em sua própria perspectiva. Isso gera julgamento do comportamento, atitude ou sentimento, levando a reação ao caráter aconselhativo, podendo agravar os sentimentos negativos do outro (Del Prette \& Del Prette, 2017; Dohrenwend, 2018). Já a simpatia é vista como prática social instintiva que auxilia no início das relações. Ela identifica o sentimento do outro e gera a concordância, sem haver qualquer reflexão ou compreensão, isso leva a sentimentos de piedade, que também refletem negativamente (Silva, 2017).

Diante de tais colocações, mesmo que os participantes não tenham demonstrado grandes imprecisões compreensivas em suas respostas, enfatiza-se a necessidade de que tais elucidações de significados da empatia sejam constantemente prezadas ao longo da formação do enfermeiro, principalmente no cuidado ao paciente queimado.

$\mathrm{Na}$ categoria 2, os participantes expõem que a empatia caracteriza-se como uma ferramenta de cuidado que contribui com a ética e a humanização do cuidado, assim como fomenta a criação do vínculo e, ainda, a resiliência para o trauma e o distúrbio da autoimagem nos indivíduos acometidos.

Sabe-se que, especialmente para o paciente grande queimado, os conhecimentos técnico-científico e uso de tecnologias duras são essenciais para sua recuperação. Entretanto, faz-se necessário voltar olhares para os âmbitos psicológicos, sociais e culturais com a mesma intensidade que se dedica aos aspectos biológicos (Santos, Araujo \& Brandão, 2018).

Neste contexto, a empatia aliada à efetiva comunicação verbal e não verbal, estabelece a relação de vínculo entre o paciente e profissional, gerando um ambiente de confiança, onde inseguranças e angústias podem ser expostas, permitindo compreender e intervir nas percepções do paciente e da família, por meio de um plano de cuidados individualizado e humanizado (Savieto \& Leão, 2016; Montezeli, Pereira, Santos, Haddad \& Caveião, 2018). 
Outro aspecto mencionado pelos estudantes foi a ética profissional. Ao serem consideradas as diversas causas de uma queimadura, é possível que algumas caminhem em desacordo com valores pessoais dos profissionais. Tais questões podem criar lacunas para o cuidado adequado, portanto, exercer empatia pode minimizar esse conflito. Isso ocorre pois, antes de permitir a interferência de juízos de valor, o profissional irá empatizar com a vivência do paciente, tornando esta vivência sua, ou seja, compreendendo os sentimentos, minimizando julgamentos e mantendo o sigilo (Montezeli et al., 2018; Grzibowski \& Barea, 2016).

Ainda sobre as representações subjetivas do cuidado favorecidas pela empatia, na ótica de acadêmicos de enfermagem, tem-se que esta colabora para o enfrentamento das queimaduras e suas complicações, levando o paciente ao caminho da resiliência, inclusive no concernente às questões de distorção da autoimagem e autoestima.

A autoestima se caracteriza pelas percepções positivas de si mesmo, construindo o autovalor. Dessa forma, dos traumas e das cicatrizes da queimadura emergem sentimentos negativos que interferem na qualidade de vida do paciente. Cônscio disto, o enfermeiro deve considerar essa complicação no processo de reabilitação e a empatia pode ajudar o profissional a direcionar o paciente na readequação de suas atividades cotidianas, fazendo com que ele entenda que não é o fim, mas uma nova vida (Montarroyos, De Lima Cabana, De Lima \& Albuquerque, 2016).

Os excertos dos depoimentos dos participantes até aqui discutidos reforçam a premissa de que a visão biomédica e curativa mostra-se obsoleta e limitada, já que ignora questões subjetivas importantes para a saúde do indivíduo e comunidade. Como complemento, a terceira categoria empírica explana que a empatia é uma ferramenta de apoio que auxilia a enfermagem a consolidar o cuidado focado na pessoa e na família, de maneira personalizada e que envolva o estado subjetivo, cultural e social (Savieto \& Leão, 2016).

A Sistematização da Assistência de Enfermagem (SAE) é um instrumento que o enfermeiro essencialmente utiliza em sua prática, para garantir-lhe cientificidade. Assim como percebido pelos entrevistados, para que a SAE seja desempenhada de forma correta, os profissionais precisam embrenhar-se de empatia, em razão de que esta é a ponte direta entre as necessidades, expectativas e limites do paciente e aquilo que o profissional pode oferecer em seu atendimento (Leal et al., 2019).

Isso se dá, visto que a empatia estabelece a relação de confiança e ajuda entre o profissional e o paciente, permitindo a compreensão da perspectiva do paciente diante dos seus problemas. Isto ajuda o profissional a elaborar um plano de cuidados que priorize essas necessidades e que o integre ativamente no processo de cuidar. Quando o profissional se dedica e compartilha sentimentos e vivências pessoais com o paciente, a relação empática torna-se mútua, facilitando ainda mais o processo de cuidar (Savieto \& Leão, 2016).

A associação de SAE com a empatia leva ao aumento da qualidade da assistência por dois impactos: o primeiro é o norteamento dos diagnósticos de enfermagem, focalizando o cuidado no que realmente é prioritário para o paciente e, segundo, por tornar a assistência mais segura ao paciente, visto que, a partir do momento em que se compreende o outro, passa-se a querer ser tratado como ele, minimizando desatenção, intolerância e egoísmo (Santos, Araujo \& Brandão, 2018; Do Nascimento Pereira et al., 2019; Albuquerque et al., 2019).

Por fim, a categoria 4 aborda as representações sociais que a empatia, ou a falta dela, trouxeram aos acadêmicos em sua vivência no CTQ. Em concordância com as pontuações efetivadas pelos estudantes, a empatia depende das experiências e valores de cada um, portanto, para que ela seja alcançada, deve-se iniciar uma prática de autoconhecimento sobre as próprias crenças, opiniões, expectativas, regras, limites e outras questões que possam interferir na capacidade de colocar-se na perspectiva do outro (Del Prette \& Del Prette, 2017).

$\mathrm{O}$ aperfeiçoamento da empatia também auxilia os profissionais a enfrentarem os problemas relacionados à interação com pacientes e equipe, evitando ou contornando circunstâncias causadoras de estresse. A manutenção do vínculo e a estabilidade do ambiente também são evidenciadas com o uso da empatia (Antoniolli et al., 2018). 
Por outro lado, a falta da empatia gera sentimentos negativos que também podem interferir no processo de cuidar, como pode ser notado nos diálogos dos participantes. Ainda que não justifique, tem-se que a falta de empatia decorre, muitas vezes, da sobrecarga de trabalho e situações conflituosas, que dificultam a aceitação da perspectiva do outro, desafiando a relação profissional-usuário-família, sendo que os profissionais da enfermagem são os mais suscetíveis, já que estão em íntimo contato com ambientes desfavoráveis (Albuquerque et al., 2019).

Há estudos que demonstram que, quanto maior o nível de estresse do profissional, menor é a sua empatia. Todavia, outros demonstram que quanto maior for o tempo de trabalho, maior sua empatia, justificado pela quantidade de experiências que este adquire ao longo do tempo. Qualquer que seja o motivo, vale reforçar que a carência da empatia pode impactar negativamente em competências essenciais dos profissionais, como a comunicação, a qual pode deixar de ser efetiva e flexível (Albuquerque et al., 2019; Yuguero et al., 2019; Giménez-Espert, Prado-Gascó \& Valero-Moreno, 2019).

\section{Considerações Finais}

A empatia é uma habilidade essencial para a prática da enfermagem, contribuindo para um cuidado integral, humanizado e de qualidade, principalmente ao paciente grande queimado. Sabe-se, também que, além de depender das experiências e vivências de cada um, pode ser incentivada desde a formação acadêmica para que os profissionais adquiram um olhar voltado à perspectiva de sua clientela, permitindo o fortalecimento do cuidado, vínculo, comunicação e ética.

Com o levantamento das categorias deste estudo, foi possível evidenciar que a empatia repercute no cuidado ao paciente queimado para além da comunicação, sendo configurada como uma ferramenta que auxilia na consolidação de um cuidado integral por meio da SAE. Também influencia positivamente no âmbito pessoal e profissional dos estudantes, despertando outras habilidades sociais como o automitoramento.

Compreender as representações sociais dos acadêmicos de enfermagem acerca da assistência ao paciente queimado, bem como a maneira que estas alteram sua forma de produzir e compreender o cuidado, auxilia no aprimoramento técnico e científico dos futuros profissionais, proporcionando a inserção de um conhecimento subjetivo em suas carreiras.

Assim, estima-se que este estudo possa instigar as instituições de ensino e de saúde a incluírem em seu cotidiano uma prática empática, valorizando o desenvolvimento e o aprimoramento de habilidades sociais, a fim de melhorar as relações interpessoais com as diversas clientelas.

Mesmo que os achados aqui discutidos tenham importância para a formação de enfermeiros alicerçados em práticas empáticas, é valido mencionar que esta investigação possui limitações. A primeira delas se dá pelo fato de ter sido realizada em apenas uma localidade; a segunda está relacionada à ambiência e à clientela em questão em que se desenvolveu o estudo, ou seja, o universo das queimaduras, uma vez que, por si só, este já pode causar percepções perturbadoras àqueles que não convivem cotidianamente com suas particularidades. Assim, recomenda-se ampliação investigativa em outras realidades e em outras áreas de atuação assistencial do enfermeiro.

\section{Referências}

Albuquerque, M. C. S., Souza D. F. S. D., Maynart W. H. D. C., Bezerra L. F. D., Cassimiro A. R. T. D. S. \& Cavalcante J. C.(2019). Empatia dos profissionais de enfermagem de um serviço hospitalar de emergência. Texto Contexto Enfermagem, 28, e20170406. http://dx.doi.org/10.1590/1980-265XTCE-2017-0406.

Alves, R. M., Alves J. B., Menezes, M. H. D. D. \& Moraes, A. (2017). Estratégias de ensino e aprendizagem no internato hospitalar de enfermagem de um currículo integrado. Journal of Nursing UFPE on line, 11(11), 4289-4297. https://periodicos.ufpe.br/revistas/revistaenfermagem/article/view/23072.

Antoniolli L., Echevarría-Ruanilo M. E., Rosso L. H., Fuculo J. P. R. B., Dal Pai D. \& Scapin S. (2018). Estratégias de coping da equipe de enfermagem atuante em centro de tratamento ao queimado. Revista Gaúcha de Enfermagem [Internet], 39, e2016-0073. https://doi.org/10.1590/1983-1447.2018.20160073 .

Bardin L. (2011) Análise de conteúdo. Edições 70. 
Conselho Nacional de Saúde. Resolução $n^{\circ}$ 466, de 12 de dezembro de 2012. Diretrizes e normas regulamentadoras de pesquisas envolvendo seres humanos. http://conselho.saude.gov.br/resolucoes/2012/Reso466.pdf.

Del Prette A. \& Del Prette Z. A. P. (2017). Competência Social e Habilidades Sociais: manual teórico-prático. Vozes

Do Nascimento P. G., De Abreu R. N. D. C., Bonfim I. M., Rodrigues Â. M. U., Monteiro L. B. \& Sobrinho J. M. (2017). Relação entre sistematização da assistência de enfermagem e segurança do paciente. Enfermagem em Foco, 8(2), 21-25. https://doi.org/10.21675/2357-707X.2017.v8.n2.985.

Dohrenwend A.M. (2018). Defining Empathy to Better Teach, Measure, and Understand Its Impact. Academic Medicine, 93(12), 1754-1756. DOI: 10.1097/ACM.0000000000002427.

Fontanella, B. J. B., Ricas J. \& Turato E. R. (2008) Amostragem por saturação em pesquisas qualitativas em saúde: contribuições teóricas. Cadernos de Saúde Pública, 24(1), 17-27. https://www.scielosp.org/article/csp/2008.v24n1/17-27/.

Giménez-Espert M. C., Prado-Gascó V. J., \& Valero-Moreno S. (2019). Impact of work aspects on communication, emotional intelligence and empathy in nursing. Revista Latino-Americana de Enfermagem, 27, e3118. https://doi.org/10.1590/1518-8345.2933.3118.

Grzibowski S. \& Barea R. (2016). Empatia e Ética na fenomenologia de Edith Stein. Revista Ágora Filosófica, Santa Maria, 1(2), 34-46. DOI: 10.20399/P1982-999X.2015v1n2pp34-46.

Júnior, A. C. L., Azevêdo, A. V. S. \& Crepaldi, M. A. (2017). Comunicação entre equipe de saúde, família, criança em unidade de queimados. Psicologia em Estudo, 22(4), 623-634. http://periodicos.uem.br/ojs/index.php/PsicolEstud/article/view/35849.

Leal L. A., Soares M. I., Da Silva B. R., De Souza Brito L. J., Bernardes A. B. \& Henriques S. H. (2019). Competências profissionais para enfermeiros hospitalares: uma análise documental. Revista de Enfermagem do Centro Oeste Mineiro, 9, e3249:1-10. http://dx.doi.org/10.19175/recom.v9i0.3249.

Montarroyos A. T. V., De Lima Cabana M. C. F., De Lima C. F. \& Albuquerque A. K. B. (2016) Autoestima em pacientes adultos com queimaduras. REVISTA HUM@NAE, 10(2), 1-27. http://www.humanae.esuda.com.br/index.php/humanae/article/view/543/168.

Montezeli J. H., Pereira S. A. G., Santos E. S., Haddad M. D. C. F. L. \& Caveião C. (2018). Polaridades vivenciadas por enfermeiros no uso das habilidades sociais em um centro de tratamento de queimados. Enfermagem Brasil, 17(6), 670 677. https://doi.org/10.33233/eb.v17i6.2354.

Moscovici S. (2013) Representações sociais: investigações em psicologia social. Vozes.

Santos A. B. V., Araujo R. R. C. P., \& Brandão E. C. (2018). A humanização no cuidado aos pacientes vítimas de queimaduras. Revista de Enfermagem da FACIPLAC, 1(1), 1-19. http://revista.faciplac.edu.br/index.php/REFACI/article/view/505.

Savieto R. M. \& Leão E. R. (2016). Assistência em enfermagem e Jean Watson: uma reflexão sobre a empatia. Escola Anna Nery Revista de Enfermagem [Internet]. 20(1): 198-202. http://www.scielo.br/scielo.php?script=sci_arttext\&pid=S1414-81452016000100198\&lng=en. https://doi.org/10.5935/14148145.20160026.

Silva H. S. M. (2017). Empatia no curso de medicina e internato médico. Tese (Doutorado) Faculdade de Medicina Lisboa, 1-22. http://hdl.handle.net/10451/31372.

Yuguero O., Forné C., Esquerda M., Pifarré J., Abadías M. J. \& Viñas J. (2017). Empathy and burnout of emergency professionals of a health region: A crosssectional study. Medicine on line, 96 (37), e8030. https://dx.doi.org/10.1097/MD.0000000000008030. 